\title{
Implementando a estratégia Product-Led Go-To-Market em startups na fase de escalabilidade: um estudo de caso
}

\author{
Marcela Azevedo Cordeiro de Melo \\ Universidade Federal de Pernambuco, Centro de Informática, Recife, Pernambuco, Brazil \\ macm3@cin.ufpe.br
}

\begin{abstract}
Startups são empresas que têm o objetivo de encontrar uma solução viável e de baixo custo para um problema enfrentado por um grupo de pessoas, fornecendo um serviço ou produto, através de um modelo de negócios escalável. Essas organizações, no entanto, enfrentam uma série de desafios que tendem levá-las ao fracasso. Ao chegar na fase de escalabilidade, na qual se faz necessário aumentar o número de clientes, as startups enfrentam diversos impasses sobre qual planejamento estratégico seguir. Devido a pouca literatura existente sobre uma recente estratégia de aquisição de clientes, este artigo almeja entender os benefícios, desafios e as principais lições aprendidas ao colocar em prática a estratégia Product-Led Go-To-Market. Dessa forma, é apresentado um estudo de caso em uma startup que provê um software como serviço e que se encontra no momento de transição de estratégias ao implementar conceitos estratégicos do Product-Led Go-To-Market. Os resultados indicam que as experiências que o cliente têm com o produto atuam como fator crucial no crescimento da empresa. Além disso, adquirir novos clientes através da própria base de dados da organização permite que a startup possa entrar na fase de escalabilidade com menos custo e tomadas de decisões com menos riscos.
\end{abstract}

Keywords: Startups, Estratégia, Métricas, Produto, Escalabilidade, Aquisição, Experiência, Clientes.

\section{Introdução}

Nos últimos anos, o poder da tecnologia de informação vem crescendo num ritmo tão acelerado que atingiu o nível de maturidade de influenciar na economia mundial de todos os segmentos do mercado. Nunca foi tão simples e barato criar uma pequena empresa que oferece um serviço digital, graças aos serviços de hospedagem na nuvem, software de código aberto, software como um serviço (SaaS), colaboração em tempo real, processamentos onipresentes de pagamento, entre outros. É dessa forma que mais de 1.35 milhões de startups de tecnologia nascem todo ano [1] a fim de encontrar, validar e resolver um problema através de um modelo de negócios escalável e com o menor custo possível.

Em contrapartida, é visto que $90 \%$ dessas startups falham e, dessas, $42 \%$ falham por, simplesmente, não atender uma necessidade concreta do mercado [1]. 
É um dado alarmante porque, além dos números serem altos, mostra que a fórmula básica de ter uma boa ideia, colocá-la em prática e vendê-la não significa que o negócio terá sucesso. Outro motivo relevante dessas startups falharem é que a maioria dos fundadores não sabe em quais funcionalidades e segmentos de clientes focar. Eles recebem conselhos contraditórios e, quando chegam no momento de escalar, apesar de obterem feedbacks qualitativos e quantitativos, ainda existem desafios ao ler os dados, interpretá-los e tomar decisões a partir deles. Por isso, é necessário realizar um planejamento estratégico objetivo com métricas verdadeiramente relevantes e um entendimento do mercado no qual o negócio está inserido.

A Even3, startup brasileira, objeto de estudo deste artigo, foi formalmente fundada em 2016, por três desenvolvedores, com o intuito de atender demandas administrativas de simples congressos científicos. Hoje, a plataforma que foi construída para realizar o gerenciamento de eventos acadêmicos e científicos consegue agregar desde inscrições até a produção dos Anais do evento, além de possuir mais de 14 mil eventos realizados. O boom inicial da empresa deve-se ao fato da solução resolver um problema real enfrentado por diversas pessoas na academia brasileira. Essa academia, que produz a maior quantidade de artigos científicos da América Latina e é $13^{\circ}$ no mundo [2], carecia de uma solução prática, intuitiva e financeiramente viável.

O sistema, inicialmente feito para suportar apenas um pequeno congresso, chamou atenção das instituições ao agregar todas as funcionalidades que um organizador de evento científico precisa em apenas uma única plataforma. Porém, com toda a facilidade de entrar no mercado de tecnologia, surgem algumas concorrências que podem não entregar o mesmo valor, mas acabam conquistando uma parcela de clientes por oferecerem preços mais baixos. Então, como continuar crescendo em um mercado altamente competitivo?

A resposta é focar no usuário final e fugir de inconsistências na sua estratégia de negócios. Focar no usuário não significa entregar exatamente o que ele pede, mas sim entender o contexto no qual ele está inserido e, consequentemente, suas verdadeiras necessidades. Por outro lado, as inconsistências falam de tomadas de decisões feitas prematuramente, tais como: contratar uma grande quantidade de profissionais, possuir o foco único no aumento do lucro, ter excesso de planejamento sem um feedback regular, investir em escalar sem encontrar a adequação do produto com o mercado, entre outras [1]. Startups que apresentam essas inconsistências, tendem a escalar de forma prematura, possuindo mais chances de falharem.

Em 2019, após 3 anos de mercado, a Even3 enfrenta justamente a fase crítica para qualquer negócio: escalabilidade. Essa fase envolve vários desafios, tais como, garantir um maior número de clientes, porém, mantendo o custo baixo, fazendo com que os gastos não cresçam de maneira proporcional ao faturamento. São inúmeras perguntas que a empresa precisa responder de forma estratégica e sustentável. A empresa vai decolar ou quebrar? Qual é o cliente ideal? Como manter o modelo de negócios estruturado e firme mesmo com o crescimento?

Murray McCaig, consultor na MaRS, descreve a tradicional abordagem go-to-market (GTM), que se baseia, basicamente, em criar um planejamento 
detalhado utilizando recursos internos e externos a fim de entregar uma proposta de valor única para seus clientes e adquirir vantagens competitivas [3]. Encontrar esse alinhamento perfeito entre o público e o produto acaba atuando como um acelerador na fase de escalabilidade da startup. Para isso, a Even3 decidiu, recentemente, realizar uma mudança de paradigma na forma de atrair novos clientes. No lugar de depender estritamente dos times de marketing e comercial para captar os potenciais clientes (leads), a ideia é que o próprio produto possa conduzir o usuário e convertê-lo em venda dentro da plataforma.

Neste artigo será conduzido um estudo de caso sobre uma startup, Even3, para entender as causas e consequências das mudanças comportamentais e estratégicas da principal funcionalidade da plataforma: a criação do evento. Tem-se como objetivo retratar uma série de recomendações para a empresa, através de dados coletados antes e depois das mudanças no planejamento estratégico e na interface do produto, a fim de ajudá-la a realizar melhores tomadas de decisões na fase de escalabilidade. Este artigo está estruturado em 6 seções. A seção 2 fornece uma revisão da literatura sobre startups e scaleups, planejamento, estratégias e métricas. A seção 3 detalha o método de pesquisa usado para conduzir o estudo de caso, incluindo a coleta e análise de dados. A seção 4 apresenta os resultados do estudo de caso, comparando com números reais da empresa. A seção 5 apresenta uma reflexão crítica sobre as lições aprendidas para a empresa. Finalmente, a seção 6 traz as contribuições deste trabalho, apresenta as limitações da pesquisa e discute ideias dos próximos passos para a empresa.

\section{Background}

\subsection{Startups e Scaleups}

Na literatura, Camel [4] foi o primeiro a surgir com o termo startup, em 1994, ao realizar um estudo de como essas empresas eram particularmente bem sucedidas, com o objetivo de defender mais pesquisa na área de desenvolvimento de software, a fim de expandir o sucesso para outras áreas da tecnologia. Para Reis [5], startups são instituições que criam produtos e serviços num cenário de incerteza. Paralelamente, Blank [6] define startups como organizações temporárias que têm o objetivo de construir um modelo de negócios escalável, repetitivo e lucrativo. O conceito de Blank consegue diferenciar bem startups e pequenos negócios, já que esses últimos não têm, necessariamente, a intenção e o objetivo de crescer. No mais, alta incerteza e evolução rápida são duas características fundamentais que melhor diferenciam startups e companhias mais estabelecidas.

Em contrapartida, Marian Zajko [7] expõe que startup é apenas a fase inicial do ciclo de vida de uma empresa. Se os fatores externos e internos forem favoráveis e se a empresa sobreviver, pelo menos, 2 anos, o negócio deve seguir para a fase de crescimento ou escalabilidade. Fase essa que é crucial para a organização, já que os recursos ainda são escassos, o lucro é baixo ou inexistente e os desafios para se manter no alinhamento entre produto e o mercado são imensos.

O estágio de escalabilidade, quando a startup se torna scaleup, é um momento bastante esperado pelos empreendedores, pois confirma que o produto ou 
serviço da organização tem viabilidade econômica própria, ou seja, existe uma demanda real naquele mercado. Porém, essa ansiedade é muito prejudicial, já que pode encaminhar a empresa para um processo prematuro de crescimento acelerado mas insustentável com várias inconsistências no negócio [1].

\subsection{Indicadores Chave de Desempenho (KPI)}

Empresas de diferentes portes precisam de uma forma de monitorar os resultados e garantir que o plano estratégico está sendo implementado. Para isso, essas organizações elaboram um conjunto de indicadores chave de performance do negócio, as chamadas KPIs (Key Performance Indicators). Michael Schrage e David Kiron (2018), no relatório de pesquisa Leading With Next-Generation Key Performance Indicators, definem KPIs como "the quantifiable measures an organization uses to determine how well it meets its declared operational and strategic goals".

Historicamente, KPIs tem um viés retrospectivo medindo custos, receitas e lucros passados, oferecendo poucas informações sobre qual caminho a companhia deveria seguir. Entretanto, Robert Kaplan e David Norton [8] propuseram, em 1992, o framework Balanced Scorecard que incorporou informações financeiras e não-financeiras com o objetivo de orientar as empresas com táticas e estratégias de curto a longo prazo. Mais recentemente, o framework de Objectives and Key Results (OKRs), estruturado por Andrew Grove [9], mostrou ser bastante popular entre as empresas de tecnologia para estabelecer, comunicar e acompanhar as metas das organizações.

Definir um conjunto de KPIs não é uma tarefa fácil e depende do segmento no qual a empresa está inserida. Dessa forma, as métricas tradicionais e financeiras são adotadas inicialmente, por exemplo: quanto a empresa está ganhando de receita, quanto se gasta em ações de marketing, quantos clientes a empresa tem, entre outras. Esses indicadores apenas se referem ao passado e, embora sejam importantes, apenas indica as necessidades de ações corretivas.

Entretanto, uma pesquisa revelou que 38\% das empresas entrevistadas têm seus 3 principais indicadores de desempenho (KPIs) centrados no cliente [10]. Além disso, a mesma pesquisa traz a estatística de que $63 \%$ dos entrevistados estão usando KPIs para desenvolver uma visão integrada e única do seu consumidor. Paralelamente, Mimi An, ao realizar um estudo para o HubSpot [11], viu que 77\% dos clientes compartilharam suas experiências positivas com produtos ou serviços e que organizações em crescimento tem $21 \%$ mais chances de priorizar o sucesso dos seus clientes do que organizações que estão estagnadas ou em declínio.

Dessa forma, fica notório que o consumidor está cada vez mais no centro do negócio e esse movimento vem ganhando força no mundo digital. Então, um novo pilar surge como uma vantagem competitiva das empresas: a experiência do consumidor.

\subsection{Experiência do consumidor}


Christopher Meyer and André Schwager [12], definem experiência do consumidor como toda e qualquer tipo de interação entre o cliente e a empresa, seja direta ou indiretamente. Essa definição está alinhada com o ponto de vista de Harley Manning, vice-presidente da Forrester, quando ele diz que experiência do consumidor envolve a percepção que o cliente tem da marca, produto ou serviço, através dessas interações [13]. As interações indiretas são aquelas que envolvem impactos não planejados com a marca e pode ser resumida a diálogos boca-a-boca, críticas, recomendações, reportagens, entre outras. Do outro lado, as interações diretas são aquelas que geralmente são iniciadas pelos próprios consumidores e assumem a forma de uma compra efetuada ou uso do produto. Essa concepção abrange todos os aspectos que a organização oferece: produto e serviço, marketing, como o produto é vendido, confiabilidade no uso dos dados pessoais, facilidade de uso, atendimento, e assim por diante. Por isso é destacado a importância de um alinhamento com toda a empresa para que o objetivo de entregar a melhor experiência para o consumidor seja atingido.

Embora esse tópico esteja sendo abordado com mais veemência nos últimos anos da era da transformação digital, ele sempre existiu, seja a empresa o definindo de forma consciente ou não. O consumidor sempre terá uma experiência - boa ou ruim - ao entrar em contato com o produto ou serviço. Muitas organizações dizem priorizar e integrar esse pilar em sua cultura [10], englobando todos os aspectos da empresa, porém, poucas estão dispostas a disponibilizar recursos necessários para tal. Quando se direciona recursos para esse fim, a ausência de um conhecimento maior sobre seu consumidor faz com que as pistas que os clientes passam para as empresas ao realizar alguma interação não sejam utilizadas da maneira mais proveitosa.

Essa falta de foco, juntamente com o alto desgaste do cliente ao possuir tantas possibilidades de serviços, significa que muitas empresas estão diminuindo seu potencial de crescimento. No mercado atual, competitivo e globalizado, onde existem vários produtos concorrentes fornecendo as mesmas funcionalidades, com a mesma faixa de preço e a mesma facilidade de acesso, como o cliente vai escolher qual utilizar?

Pesquisas mostram que é o produto da empresa que provê a melhor experiência. Corroborando com essa visão, Peter Kriss, realizou um estudo [14] onde foi revelado que usuários que obtiveram a melhor experiência gastam 140\% a mais do que aqueles que tiveram uma experiência pior. Além disso, um cliente que teve uma experiência ruim, tem apenas $43 \%$ de chance de continuar sendo cliente daquela organização um ano depois. Já clientes que tiveram melhores experiências, têm $74 \%$ de chance de permanecer como membro por pelo menos mais um ano.

O sucesso do cliente, que é o resultado de uma experiência excelente, leva o consumidor a interagir mais com a marca, ser mais leal e compartilhar suas interações com a organização com mais pessoas. Dessa forma, o cliente contribui com a divulgação da empresa a partir da sua experiência positiva com o produto.

\subsubsection{Experiência do usuário}


Um componente muito importante do design de produtos é a experiência do usuário. De acordo com Albert e Tulis [15] a experiência do usuário possui 3 principais características: (1) existe um usuário envolvido; (2) o usuário interage com alguma interface; (3) a experiência é observável e mensurável. O termo foi popularizado por Don Norman, em seu livro "The Invisible Computer" (2009), para englobar todas as interações entre o ser humano e a interface: como a interface é percebida, aprendida e utilizada. Esses aspectos formam uma base para satisfazer as necessidades do usuário final.

Essas interações do usuário com as interfaces do produto ou serviço podem ser mensuradas através de métricas como: taxas de sucessos e de erros dos usuários ao realizar determinada ação, taxa de abandono, tempo para completar determinada tarefa, cliques para chegar na ação final, entre outras.

Fica claro, a partir das definições e métricas, que a experiência do usuário está mais relacionada aos contatos do consumidor com interfaces e seus respectivos níveis de usabilidade. Um exemplo de uma experiência do usuário ruim pode ser visto em e-commerce, quando, ao tentar realizar uma compra um cartão de crédito e é evidenciado uma mensagem de erro, mas não o erro exato. Como o usuário poderia corrigir suas ações para completar aquela tarefa? A resposta é: ajustar o texto da mensagem de erro para uma mais específica.

Garret [16] afirma que a experiência do usuário é o fator mais significativo de lealdade do consumidor com a organização, visto que a fidelidade é construída a partir de experiências positivas. Outros autores, como Pine e Gilmore [17], ressaltam a importância da experiência do usuário como uma vantagem estratégica do produto ou serviço, que pode resultar em mais vendas, mais leads, mais consumidores dispostos a pagar mais caro, maior ticket médio, e assim por diante. Mais uma vez, a experiência do cliente com o produto atua como principal propagador do mesmo. Logo, empresas que querem oferecer a melhor experiência para os seus consumidores precisam buscar o alinhamento com sua estratégia de adquirir novos clientes.

\subsection{Planejamento estratégico}

\subsubsection{Estratégia Go-To-Market (GTM)}

Segundo Lawrence [18], a estratégia Go-To-Market (GTM) é um planejamento da empresa para encontrar os clientes certos no mercado, através dos canais de distribuição apropriados, com o produto e uma proposta de valor adequados. Embasando essa definição, Nick Bonfiglio e Mickey Alon [19] afirmam que GTM é um plano de ação com o objetivo de fazer com que a empresa adquira e mantenha novos clientes a partir de processos repetitivos e escaláveis. Repetitivos significa que a empresa pode esperar os mesmos resultados para ações definidas em um playbook de GTM que já foi utilizado anteriormente. Já escaláveis quer dizer que a empresa pode contratar novos colaboradores e treiná-los a partir do playbook GTM. Aplicando esses conceitos, a empresa pode obter um crescimento exponencial na aquisição de novos clientes [19]. 
Para isso, os autores descrevem que a experiência que a organização fornece ao consumidor deve estar alinhada com a estratégia GTM [18, 19]. Esse alinhamento precisa ocorrer devido ao fato de que um relacionamento contínuo com o cliente, com diversas interações em fases distintas, define a empresa e molda a oportunidade de crescimento a longo prazo da mesma. Então, desde o momento que o consumidor pesquisa sobre a organização até uma possível compra, são criadas experiências que são capazes de resumir o negócio e seu sucesso ou fracasso.

A estratégia GTM caracteriza os canais de distribuição de marketing, isto é, as formas que a empresa disponibiliza o produto ou serviço para as vendas, como elementos essenciais do negócio. Porém, esse argumento não demonstra a mesma força, já que a era digital trouxe uma explosão de novos canais para alcance de novos clientes [19]. Ao se dar conta de que os clientes podem migrar de canais rapidamente, a segmentação e as estratégias usadas com base neles acabam perdendo a importância.

\subsubsection{Estratégia Product-Led Go-To-Market (PLG)}

De acordo com a pesquisa feita por Frederick Reichheld [20], dependendo do mercado que a organização está inserida, adquirir um novo cliente é, em média, 25 vezes mais caro do que manter um já existente. Em paralelo, devido à explosão dos canais de distribuição, as expectativas dos consumidores está mudando, afinal, existem mais produtos e empresas para serem comparadas e testadas. Esses fatores estão sendo responsáveis por evidenciar novas perspectivas de como as empresas devem conquistar os consumidores e transformá-los em clientes que pagam pelo produto ou serviço disponibilizado.

Como resultado, surge a abordagem Product-Led Go-To-Market (PLG), na qual o próprio produto se torna o principal canal de distribuição para adquirir e reter os clientes. Nick Bonfiglio e Mickey Alon [19] definem PLG como uma estratégia para descrever processos repetitivos e escaláveis para adquirir e manter clientes, a base da Go-To-Market (GTM), mas que é impulsionada pelo comportamento e feedbacks do consumidor e durante seu uso do produto. A maneira que os possíveis clientes interagem com o produto pode ajudar a empresa a tomar melhores decisões e entregar o sucesso aos seus consumidores mais rapidamente.

Dessa forma, o modelo de vendas tradicional vira de cabeça para baixo. Ao invés de realizar um longo acompanhamento com o consumidor até a compra ser efetuada, o próprio produto fornece essa oportunidade de compra. Já a empresa começa a se preocupar em como melhorar a vida do seu cliente, com foco na experiência do usuário - quanto mais positiva a experiência, mais chances do consumidor ser convertido em comprador.

As vantagens dessa abordagem são inúmeras. O Slack, por exemplo, tem uma taxa de conversão de clientes gratuitos para clientes pagantes de $30 \%$, gerando um faturamento de 4 milhões de dólares em 3 anos e 4 milhões de usuários ativos diariamente [21]. A taxa de conversão de $30 \%$ é um número impressionante, visto que empresas do mesmo setor possuem uma taxa de, aproximadamente, 10\% [21]. 
O Slack atingiu esses números sem investir milhões no setor de marketing e sem ao menos ter um diretor de marketing (Chief Marketing Officer).

Essa nova estratégia traz consigo um novo tipo de lead - cliente em potencial - através do próprio produto, que agora é o principal canal de distribuição na aquisição dos novos consumidores. O novo lead é chamado de Product-Qualified Lead (PQL), que é definido por Wes Bus [22] como um usuário que alcançou um valor significativo ao utilizar o produto de forma gratuita. Alcançar um valor significativo quer dizer que aquele usuário teve uma experiência positiva com o serviço e demonstrou interesse em efetuar compras no produto, por meio do uso do mesmo e outros dados comportamentais. Vale ressaltar que o PQL provê um método mais preciso de rastrear a jornada do usuário e que só faz sentido utilizar esse conceito dentro de uma estratégia Product-Led Go-To-Market.

Diante do exposto, é evidenciado que negócios dirigidos pelo produto possuem algumas vantagens e acessos a ferramentas poderosas de crescimento, reduzindo significativamente os custos de aquisição de novos clientes comparado com as estratégias de marketing tradicionais. Além disso, esses negócios tendem a escalar mais rapidamente, já que conseguem comunicar e entregar o valor do seu produto ou serviço de uma forma mais dinâmica.

\section{$3 \quad$ Método de Pesquisa}

\subsection{Visão Geral}

Nesta seção, apresentamos o método de pesquisa para conduzir um estudo de caso único e exploratório na startup pernambucana Even3. A empresa estudada tem como objetivo, através de uma plataforma simples e intuitiva, dar autonomia ao usuário para que ele gerencie seu próprio evento sem a necessidade de realizar diversas tarefas manuais, aumentando assim a produtividade da organização do evento. O produto proposto pela Even3 foi inicialmente desenvolvido em 2015 para suprir uma necessidade específica de um professor da Universidade Federal de Pernambuco ao organizar uma conferência. Já a empresa foi fundada formalmente apenas em 2016, quando os 3 fundadores encontraram um mercado carente de soluções para os problemas de gerenciamento de eventos acadêmicos e científicos. $\mathrm{O}$ estudo de caso visa responder as seguintes questões de pesquisa:

QP 1 - Quais os benefícios e desafios de implantar a estratégica Product-Led Go-To-Market (PLG) na empresa Even3?

QP 2 - Quais são as principais lições aprendidas durante a implantação da estratégica Product-Led Go-To-Market (PLG) na empresa Even3?

O estudo de caso tem como base a transição de estratégia da organização para aquisição de novos clientes na plataforma. Com o intuito de não depender apenas dos clientes que vinham pelos canais tradicionais de marketing ou sales, foi adicionado um novo canal de aquisição: o próprio produto. Para esse fim, foi realizado um estudo prévio por parte dos colaboradores da empresa sobre 
Product-Led Go-To-Market que culminou numa mudança radical da interface de uma funcionalidade crucial de uma plataforma de eventos acadêmicos - a criação do evento.

\subsection{Coleta e análise de dados}

Inicialmente, foi realizada uma investigação conceitual na literatura referente ao ecossistema das startups e scale ups que facilitou a construção dos procedimentos adotados na coleta de dados. Em paralelo, a coleta e análise dos dados foi feita com base nas recomendações propostas por Robert K. Yin, no livro "Estudo de Caso" [23]. A principal fonte de dados foram entrevistas semi estruturadas com colaboradores da empresa. De forma complementar, foi utilizada a avaliação da documentação da empresa - incluindo os objetivos e indicadores chave de desempenho - e observações do dia-a-dia de trabalho na mesma, visto que a autora deste artigo desempenha a função de desenvolvedora na organização em estudo.

Como visto na revisão da literatura, a estratégia Product-Led Go-To-Market tem uma base muito forte na experiência do usuário e do consumidor. Dessa forma, também foi preparado um monitoramento de interfaces do produto, através da plataforma Hotjar $^{l}$, que buscou entender como os usuários interagem com a funcionalidade de criar o evento e como sua experiência com a plataforma se desenvolvia.

Para realizar as entrevistas semiestruturadas, foi elaborado um protocolo para guiar as entrevistas (disponível na Tabela 1). As perguntas adotadas na entrevista foram definidas com o objetivo de entender os cenários precedentes e posteriores à mudança estratégica para aquisição de novos clientes. Com isso, é esperado que seja possível relatar a importância da definição do planejamento da empresa, incluindo os indicadores chave de desempenho, e de inovações estratégicas, para o crescimento da organização.

Tabela 1. Protocolo da entrevista

\begin{tabular}{|c|c|}
\hline $\begin{array}{c}\text { Número da } \\
\text { pergunta }\end{array}$ & Pergunta \\
\hline 01 & Qual era o contexto da empresa quando foi definida a mudança de \\
estratégia?
\end{tabular}

\footnotetext{
${ }^{1}$ Disponível em: https://www.hotjar.com/
} 


\begin{tabular}{|c|c|}
\hline 05 & $\begin{array}{c}\text { Quais são os próximos passos em relação a implementação da } \\
\text { estratégia Product-Led Go-To-Market? }\end{array}$ \\
\hline
\end{tabular}

As entrevistas foram realizadas com 4 colaboradores que atuaram diretamente na estruturação e implementação da mudança de estratégia na empresa, objeto principal neste estudo de caso (Tabela 2).

Tabela 2. Funções dos entrevistados

\begin{tabular}{|c|c|c|}
\hline $\begin{array}{c}\text { Número do } \\
\text { entrevistado }\end{array}$ & Função do entrevistado & $\begin{array}{c}\text { Tempo de empresa do } \\
\text { entrevistado (em meses) }\end{array}$ \\
\hline E01 & $\begin{array}{c}\text { Sales Development Representative } \\
(\text { SDR })\end{array}$ & 9 \\
\hline E02 & Sales Closer & 36 \\
\hline E03 & Diretor de Operações e Fundador & 47 \\
\hline E04 & Sales Closer & 18 \\
\hline
\end{tabular}

As entrevistas foram gravadas com seus áudios transcritos e devidamente revisados. A seguir, a seção de Resultados é estruturada a partir das análises das respostas dos entrevistados, do monitoramento das interfaces e, paralelamente, como citado, das vivências da autora deste artigo, tanto na leitura da documentação da organização, como no seu próprio entendimento do dia-a-dia e modelo de negócios da organização.

\section{Resultados}

\subsection{Contexto da empresa}

No início de 2019, a Even3 estava começando a escalar a startup. O número de funcionários mais que dobrou em relação ao ano anterior, totalizando 18 funcionários, o escritório físico da empresa foi expandido, os clientes que pagavam estavam fidelizados e o produto tinha alcançado a brecha existente no mercado de eventos científicos. Além disso, a empresa tinha acabado de alterar a forma de cobrança do seu ticket médio e, consequentemente, houve uma mudança no seu modelo de negócios.

Para a aquisição de novos clientes, a empresa estava apostando numa nova contratação para o time de comercial com a função de realizar as prospecções praticando o outbound sales (Sales Development Representative - SDR) - uma busca de pessoas e instituições da esfera acadêmica que ainda não tinham tido contato com o produto. Porém, adquirir esses possíveis leads vindos do comercial se torna um processo muito longo e caro, ocupando muito tempo de trabalho e trazendo poucos resultados imediatos. De acordo com o entrevistado E01: 
O planejamento para o segundo trimestre do ano foi o primeiro na empresa que aconteceu com a participação de um SDR. Então, a gente focou uma parte do planejamento só em atividades que seriam direcionadas em conseguir mais oportunidades através de uma abordagem mais agressiva. O que impulsionou isso foi que, para nós do time de comercial, era interessante conseguir mais oportunidades de um jeito mais barato e mais rápido. (E01)

Dessa forma, surgiu uma ideia, através de estudos e pesquisas realizados por ambos os times de marketing e comercial, de implementar alguns conceitos da estratégia de Product-Led Go-To-Market, como ressaltado pelo entrevistado E03:

Nós fomos para um evento no fim de 2018 e lá ouvimos pela primeira vez falar sobre Product Qualified Lead. Na época, não era uma coisa que pensávamos em aplicar na empresa, mas, nos planejamentos de 2019, acabou batendo com o que o time de comercial estava precisando, que era uma nova forma de gerar mais propostas. (E03)

A empresa começou a desenvolver uma estrutura para capturar esse lead que chegava pelo próprio produto, mas a plataforma não havia sido desenhada com esse intuito. O objetivo era que o time de comercial identificasse, através do uso da plataforma, qual usuário poderia ser interessante para que eles atacassem de forma mais agressiva e vendessem mais serviços. O entrevistado E02 relata:

O gatilho que escolhemos para podermos identificar se aquele usuário pode ou não se tornar um cliente interessante pra gente foi justamente na hora que ele estava criando o evento dele. Afinal de contas ele já tá ali, dentro da Even3, demonstrando o interesse em organizar um evento através da plataforma. (E02)

Porém, o produto não estava preparado para isso. A funcionalidade de criação do evento era simplista demais e tinha como objetivo que o usuário apenas finalizasse a ação de cadastrar o seu evento na plataforma, como mostra a Figura 1.

O entrevistado E03 comenta:

Evoluir a página de criação do evento já era uma coisa que a gente queria fazer, evoluir o design e melhorar a experiência do usuário. Então casou com a necessidade emergente de fazer a segmentação do público pra ajudar o time de comercial a gerar mais oportunidades. (E03)

Cerca de 1 mês anterior à mudança da interface de criação do evento, ao realizar o monitoramento da página, foi adicionada uma pesquisa de satisfação do usuário, como uma métrica de experiência, perante aquela ação de cadastrar o evento. Assim que o usuário concluía o ato da criação, surgia a pergunta: "No geral, criar seu evento foi". A escala de 1 a 7 - sendo 1 "Muito difícil" e 7 "Muito 
fácil" - foi escolhida como opção de resposta, baseado no conceito de Single Ease Question (SEQ) [24], que é utilizada após a realização de uma ação para capturar alguma percepção do usuário em relação àquela ação. Foram obtidas 124 respostas, com $71 \%$ delas sendo a opção 7, "muito fácil", e 12.9\% sendo a opção 6.

Figura 1. Interface antiga da criação do evento

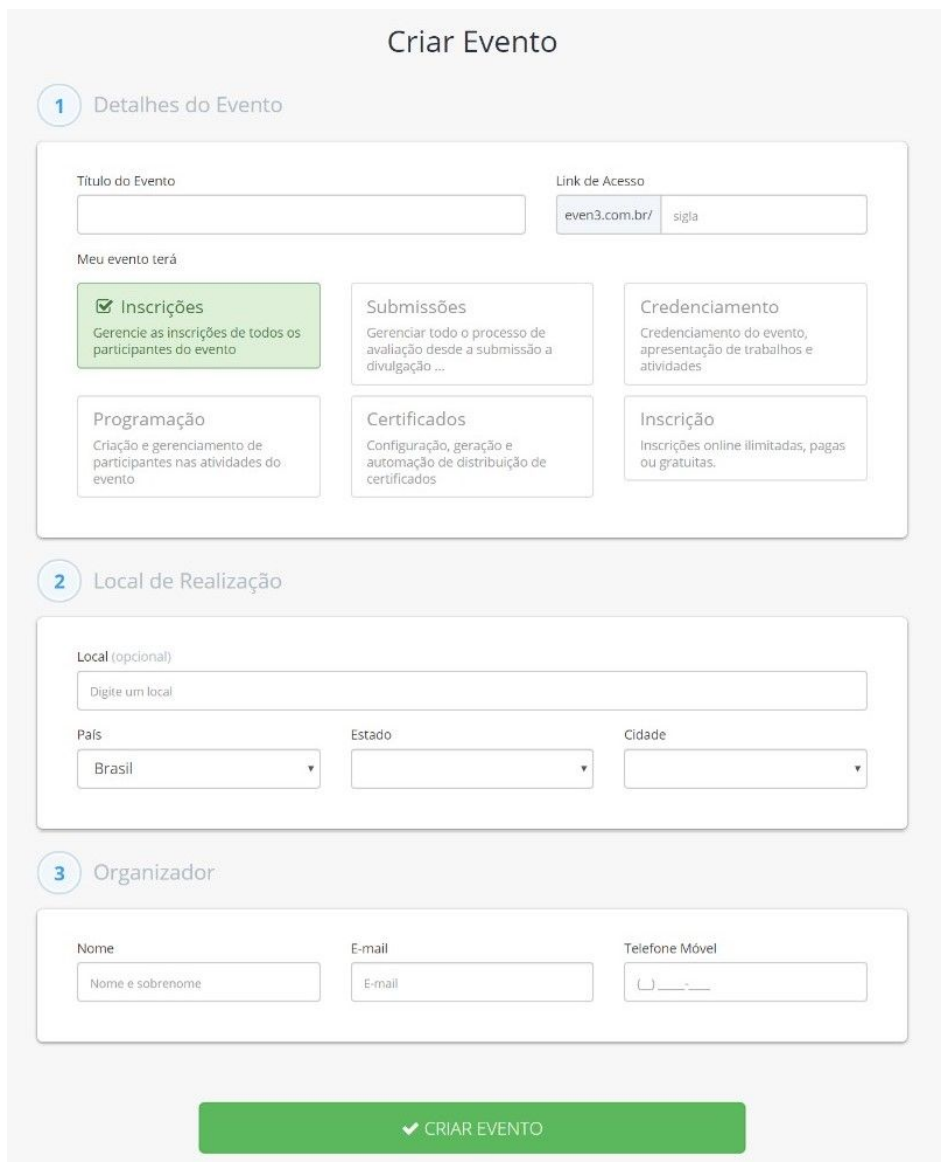

Apesar do bom resultado da pesquisa de satisfação em relação a interface de criar evento que já existia e de já possuir uma base de clientes familiarizados com a mesma, o baixo número de propostas geradas para o time de comercial ainda teve um peso maior na decisão de mudar de estratégia para adquirir novos clientes. Afinal de contas, como relata o entrevistado E03:

Fazia sentido a gente aplicar os conceitos que estudamos mesmo se era uma coisa que nenhuma outra concorrência direta nossa estava fazendo. A gente precisava começar a fazer as coisas que a gente via que encaixava com o nosso negócio, e não só fazer as coisas que todo o resto está fazendo. (E03)

Então, para acompanhar de perto a quantidade de oportunidades criadas e, a partir disso, tomar melhores decisões em relação a estratégia Product-Led Go-To-Market, foi adotado como indicador chave de desempenho do time de comercial a seguinte métrica: "Gerar X novas oportunidades" - sendo X um número qualquer, a fim de preservar a empresa em estudo. 


\subsection{Proposta de interface da plataforma visando PLG}

A nova interface de criação do evento foi ao ar, oficialmente, no fim do mês de agosto de 2019. Depois de muitos estudos de benchmarking, tanto do time de desenvolvimento em relação às melhorias da experiência do usuário, como do time de comercial ao pesquisar a fundo quais informações eram necessárias capturar do usuário no momento de criar o evento, a nova interface da funcionalidade está apresentada nas Figuras 2 a 5.

As novas telas são mais interativas com o usuário e traz uma percepção de que a plataforma está conversando com o mesmo. Além disso, a ação de cadastrar o evento foi dividida em 4 passos, cada passo com no máximo 3 inputs, para que o usuário não sinta que o formulário é cansativo e desista no meio do caminho.

Figura 2. Passo 1 da criação do evento.

\section{Vamos criar seu evento}

Qual o nome do evento?
E a expectativa de participantes?
Escolha o tipo do seu evento
-- Selecione uma opção --

Continuar »

Figura 3. Passo 2 da criação do evento.

Perfeito, conte-nos sobre você

Passo 2 de 4

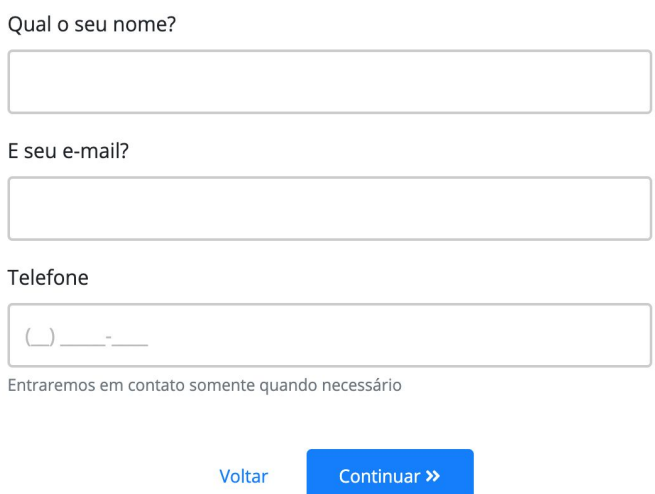


Figura 4. Passo 3 da criação do evento.

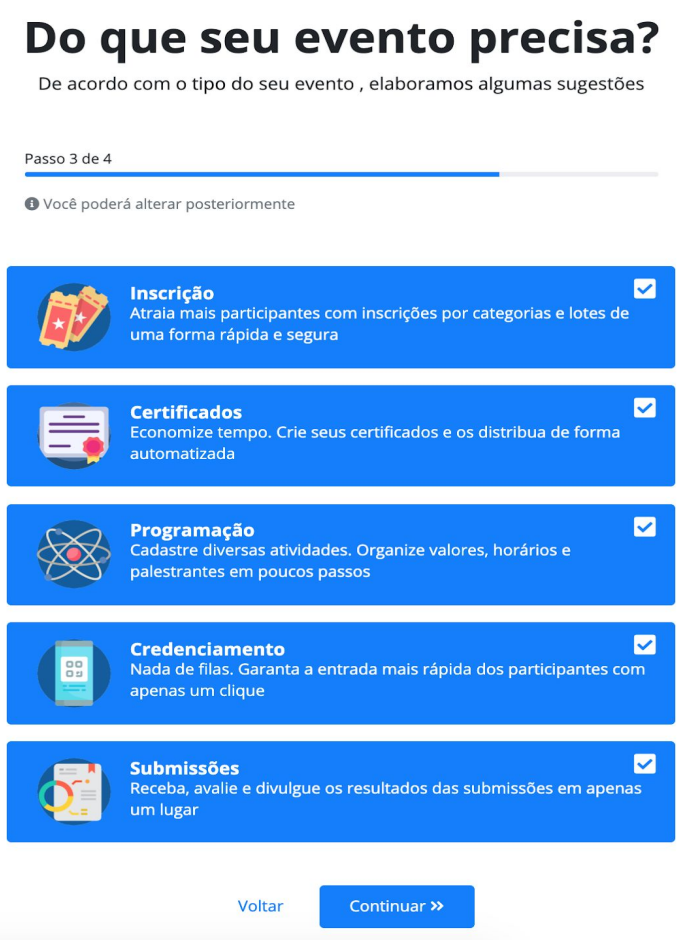

Figura 5. Passo 4 da criação do evento.

\section{Perfeito, Maria. Para finalizar...}

Passo 4 de 4

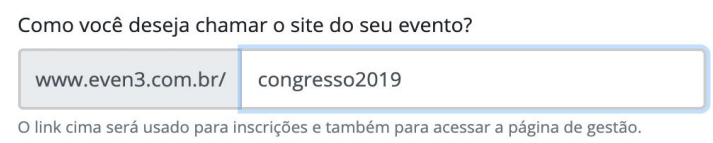

Olink cima será usado para inscrições e também para acessar a página de gestão.

Com as novas informações solicitadas ao usuário na hora de criar o evento, o time comercial tem mais fundamentos para decidir se aquele cliente tem um perfil que encaixa melhor para a Even3. Por exemplo, por ser uma plataforma de eventos científicos, um evento criado do tipo show ou festa, não é o cliente ideal para que o comercial precise atacar de forma agressiva oferecendo mais serviços. Esses tipos de filtros são importantíssimos para o comercial otimizar seu tempo, mas requer uma análise muito detalhada e crítica dos dados da base da empresa.

A página principal da plataforma também foi alterada, como mostram as Figuras 6 e 7. Atualmente, na nova versão, existe um botão a mais de "criar o evento", na parte superior direita, ao lado do botão de login, que foi criado para chamar a atenção do usuário em criar mais eventos. 
Figura 6. Página inicial da Even 3 antes das alterações

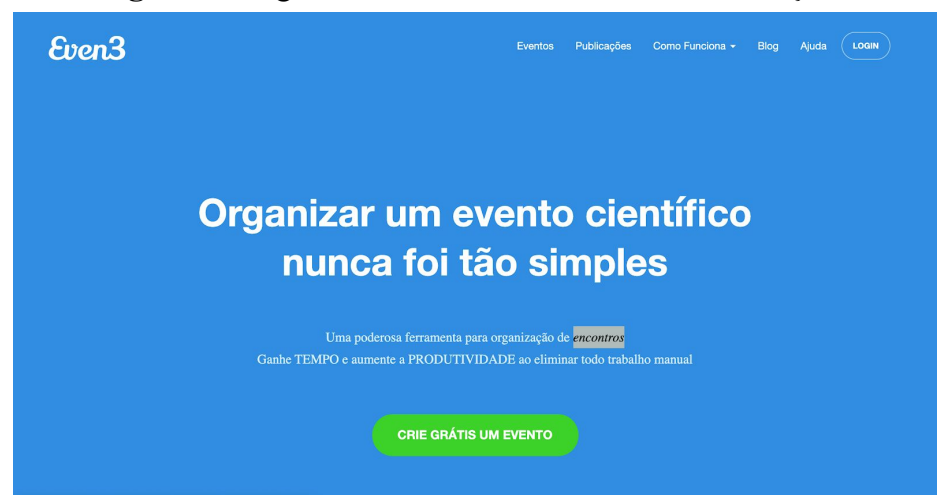

Figura 7. Página inicial da Even3 após alterações

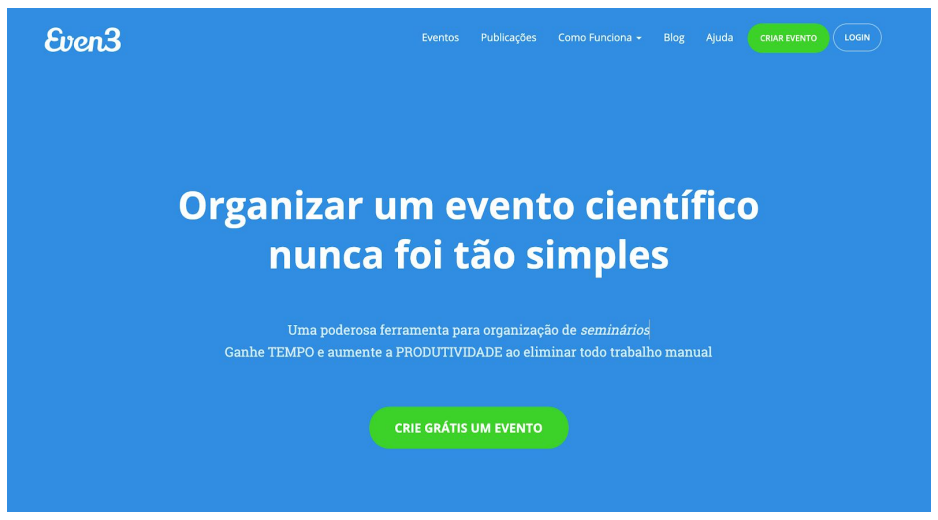

Porém, esse novo botão está trazendo alguns problemas para o negócio, visto que existem, aproximadamente, 50 relatos coletados mostrando que os usuários estavam tentando realizar seus respectivos logins na plataforma, mas acabavam se confundindo e criando um evento.

Após realizar as mudanças na interface da funcionalidade de criar o evento, a mesma pesquisa de satisfação que aconteceu 1 mês na página antiga foi realizada com a nova interface. Foi escolhida a mesma pergunta, "No geral, criar seu evento foi", com a mesma escala de 1 a 7 , sendo 1 "muito difícil" e 7 "muito fácil" e usando a mesma base da Single Ease Question (SEQ). Foram 396 respostas, sendo $77.3 \%$ delas sendo a opção 7, "muito fácil", e 10.1\% sendo a opção 6. Esse aumento de satisfação foi um dado bastante positivo, visto que a interface anterior estava desenhada e implementada daquela forma há mais de 3 anos, e trouxe uma reflexão de que a organização conhece o seu cliente.

Em relação a geração de novas oportunidades, o lead que chega através do canal do próprio produto foi muito frutífero para a organização, como relata as entrevistadas E02 e E04:

Nos últimos meses, a maior parte das propostas que foram fechadas, ou seja, a maior parte dos clientes convertidos em clientes pagantes, veio do canal do produto, foi um PQL. (E02) 
Aquela coisa de reter clientes que já existem, tentar extrair o máximo dos clientes que já existem, é bem menos trabalhoso do que buscar novos clientes. (E02)

No lugar de tentar capturar leads que sequer conheciam a plataforma, investir na nossa própria base é bem menos custoso, dado que a pessoa já está em contato com a plataforma; convencer alguém que nunca ouviu falar da Even3 a usá-la é um processo mais longo e que requer muita confiança de ambas as partes. (E04)

Ainda existem muitas dificuldades relatadas pelos colaboradores sobre essa nova estratégia de aquisição de clientes. Apesar dos números de oportunidades criadas e fechadas terem aumentado significativamente, ainda existe uma barreira quando se fala de quais dados coletar e como analisá-los, como se manifesta o entrevistado E03:

Precisamos melhorar quais perguntas fazer na hora do organizador criar o evento, porque, dessa forma, vamos saber qual segmento atacar mais. Isso está muito ligado com a coleta e análise dos dados. A partir dos clientes que estão fechando uma proposta, traçar o perfil dos eventos ideais e mudar o formulário da interface a partir disso. (E03)

Apesar do número de oportunidades novas geradas ter aumentado com a implementação do novo canal de aquisição de clientes, a taxa de oportunidades que são concretizadas em contratos extensos que fazem sentido para a empresa ainda é baixa, cerca de $2.5 \%$. O número é baixo visto que, no mercado, a média de conversão de clientes gratuitos para pagantes das empresas que oferecem um software como um serviço é de 10\% [20].

Após esse momento crucial de transição, a organização ainda tem como objetivo investir no estudo e na aplicação dos conceitos da estratégia de Product-Led Go-To-Market. O objetivo de "Aumentar a taxa de conversão de prospecção" continua sendo chave do planejamento estratégico para o crescimento da empresa e, para 2020, a empresa tem como ambição chegar no patamar dos 10\% de taxa de conversão desses novos clientes que chegam através do produto.

\section{Lições Aprendidas}

Startups precisam focar seus esforços nos seus estágios iniciais para entender o mercado que está se inserindo e, consequentemente, seus possíveis clientes. Isso vai ajudar a organização a evitar possíveis falhas que podem acarretar no fechamento da mesma antes de sequer chegar na fase de escalabilidade. Para isso, é crucial realizar segmentações para atingir esse alinhamento entre o público e mercado, mas precisa ser feito com cautela, pois ao inserir muitas restrições, o escopo de clientes pode diminuir e a startup pode atingir um número baixo de 
novas aquisições, o que se torna um impeditivo para a mesma entrar na fase de escalabilidade.

Ao chegar nessa fase, apesar da startup já ter um lugar no mercado, isso não significa que o alinhamento entre o produto e o mercado está concluído. O modelo de negócios que a startup adota no início do empreendimento não é estático e suas mudanças podem acarretar em novos segmentos e públicos para serem atingidos. Dessa forma, é acentuado a importância da estruturação dos canais tanto de distribuição, que é aquele que vai propagar a empresa, como o de aquisição de novos clientes, que é aquele que vai captar os clientes para o negócio.

No mercado atual, startups precisam agir cada vez mais rapidamente quando considera-se adoção de novas estratégias. Insights podem chegar de qualquer lado, do estagiário ao $C E O$, mas, para que isso aconteça de uma forma natural, é interessante que a empresa tenha um alinhamento dos indicadores de desempenho e objetivos gerais entre todos os times da organização, independente da função. Por isso, é destacado a relevância de reuniões táticas e operacionais que envolvam, pelo menos, uma pessoa de cada setor.

Se basear nos dados é um movimento que vem crescendo na revolução tecnológica. Esse pensamento, ao ser intrínseco na startup desde os seus estágios primários e adicionado à sua cultura organizacional, deve ser incluído de maneira mais natural nos treinamentos dos novos colaboradores. Isso forma uma base para que todos possam contribuir com novas ideias que impulsionam a empresa para o crescimento, visto que uma das maiores dificuldades em se tornar uma organização guiada a dados é saber como analisá-los e tirar conclusões dos mesmos.

A experiência que o produto fornece para o usuário é fator crucial para conversão dos mesmos em clientes pagantes. Quando o usuário tem uma boa experiência com a plataforma e, além disso, também tem boas vivências com a organização, é muito mais fácil que ele compre mais serviços da empresa, independente do custo total que ele vai ter. As experiências que o usuário têm com as interfaces e a empresa atua como agente determinante para a escolha do mesmo, perante um mercado com muitas organizações provendo o mesmo serviço. Dessa forma, é imprescindível que as startups, mesmo estando em estágios iniciais como o MVP (Minimum Viable Product), invistam seus esforços em adquirir mais conhecimento em relação a como o produto pode providenciar a melhor vivência para o usuário.

Vender para os clientes que já tiveram o mínimo conhecimento sobre o produto é muito menos custoso e deve ser alvo das startups de pequeno porte caso as mesmas decidam escalar o negócio. Atacar a própria base de dados para gerar mais oportunidades e, em consequência, mais clientes, se torna uma estratégia inteligente, visto que há poucos gastos e não é necessário grandes times para colocar os conceitos do Product-Led Go-To-Market em prática.

Em síntese, este artigo apresenta as seguintes lições aprendidas durante o estudo de caso na empresa Even3. Tais lições podem ser úteis para startups que vivenciam oportunidades e desafios de crescimento semelhantes à empresa estudada. 
1. Entender quais informações coletar dos seus clientes e como analisá-las é de extrema importância e traz resultados significativos que direcionam a organização, independente do seu tamanho.

2. Manter o alinhamento sobre métricas e objetivos da empresa entre todos os seus funcionários aumenta as chances de surgirem insights sobre novas formas de fazer negócio.

3. Atingir a própria base de dados para aquisições de novos clientes pagantes é um trabalho extremamente mais barato.

4. Vender serviços de um produto para quem já tem um conhecimento prévio do mesmo custa menos tempo.

5. A experiência que o produto provê para o usuário é um fator crítico nas tomadas de decisões dos clientes, então ela deve estar em constante evolução.

6. Pivotar estratégias e planejamentos é um processo delicado, mas deve ser feito rapidamente caso a organização esteja com os seus indicadores chave abaixo do esperado.

\section{Conclusões, limitações da pesquisa e trabalhos futuros}

Neste artigo, foi conduzido um estudo de caso na Even3, startup com quase 4 anos de mercado, que oferece um software como serviço para apoiar o gerenciamento de eventos acadêmicos e científicos. Foram entrevistados 4 colaboradores para realizar a análise do contexto da startup e quais eram as dificuldades enfrentadas para que fosse necessário pivotar a estratégia de aquisição de clientes. Ademais, foram realizadas pesquisas com os usuários e um monitoramento das interfaces da solução.

A mudança de estratégia na aquisição de clientes trouxe como benefício principal a diminuição no custo do processo de converter esses clientes em usuários pagantes na plataforma. Além disso, na seção de Lições Aprendidas, foram resumidas uma série de recomendações para startups que estão vivenciando contextos semelhantes ao da empresa Even3.

Ao conduzir este artigo, foi identificada uma limitação ao realizar a investigação conceitual sobre Product-Led Go-To-Market por se tratar de um conceito novo que grandes grandes instituições, como o Slack, estão adotando nos últimos 2 anos. Então, a pouca literatura científica a sobre essa estratégia no contexto de startups foi um impeditivo para maiores aprofundamentos. Além disso, outro entrave ao realizar essa pesquisa foi a preservação de objetivos e estratégias da empresa em estudo, Even3, que não foram expostos para não prejudicar o planejamento estratégico da empresa.

Como sugestões de trabalhos futuros, é observada uma necessidade emergente de mais pesquisas exploratórias sobre novas estratégias de aquisição de clientes, já que esse indicador de desempenho é essencial para o crescimento do negócio, visto que a fase de escalabilidade atua como um milestone no contexto de startups.

\section{Referências}


[1] Marmer, M. et al. (2011). Startup Genome Report Extra on Premature Scaling: A deep dive into why most high growth startups fail.

[2] Analytics, Clarivate. (2018). Research in Brazil: A report for CAPES by Clarivate Analytics.

[3] MaRs. The seven-step go-to-market strategy. Disponível em: https://www.marsdd.com/news/the-seven-step-go-to-market-strategy/. Acesso em: 17 nov. 2019.

[4] E. Carmel. (1994 )Time-to-completion in software package startups.

[5] E. Ries. (2011). The lean startup: How today's entrepreneurs use continuous innovation to create radically successful businesses.

[6] S. Blank. (2005). The Four Steps to the Epiphany: Successful Strategies for Products that Win.

[7] Zajko, Marian. (2017). Challenges of scaling-up process for start-ups.

[8] R.S. Kaplan, D.P. Norton. (1992). The Balanced Scorecard - Measures That Drive Performance.

[9] Niven, Paul R., Lamorte, Ben. (2016) Objectives and Key Results: Driving Focus, Alignment, and Engagement with OKRs.

[10] Schrage, Michael, Kiron, David. (2018). Leading With Next-Generation Key Performance Indicators.

[11] HubSpot. Customer Success Feeds Business Success. Disponível em: https://blog.hubspot.com/news-trends/customer-success\#LINK2. Acesso em: 17 nov. 2019.

[12] Meyer, Christopher, Schwager André. (2007). Understanding Customer Experience.

[13] Forrester. Customer Experience Defined. Disponível em: https://go.forrester.com/blogs/definition-of-customer-experience/. Acesso em: 20 nov. 2019.

[14] Kriss, Peter. (2014). The Value of Customer Experience, Quantified.

[15] Tullis, Thomas, Albert, William. (2008). Measuring the User Experience: Collecting, Analyzing, and Presenting Usability Metrics.

[16] Garret, Jesse James. (2011). The elements of user experience: User-Centered Design for the Web and Beyond.

[17] Pine II, B. \& Gilmore, J. (2013). The experience economy: past, present and future.

[18] Friedman, Lawrence G. (2002). Go-To-Market Strategy: Advanced Techniques And Tools For Selling More Products, To More Customers, More Profitably.

[19] Bonfiglio, Nick, Alon, Mickey. (2017). Mastering Product Experience in SaaS: How to Deliver Personalized Product Experiences with Product-led Go-to-Market Strategy.

[20] Reichheld, Fred. (2001). Prescription for cutting costs.

[21] OpenView. (2017). Product-Led Growth Playbook: Implementing an Effective PLG Strategy for Faster, More Cost Effective Growth.

[22] Product-Led Institute. Beginner's Guide to Product Qualified Leads (PQL). Disponível em: https:/productled.com/product-qualified-leads/\#: :targetText=A\%20product $\% 20 \mathrm{q}$ 
ualified\%20lead\%20(PQL,a\%20customer\%20than\%20other\%20leads. Acesso em: 20 nov. 2019.

[23] Yin, Robert K. (2001) Estudo de Caso: Planejamento e Métodos.

[24] Sauro, Jeff \& Dumas, Joseph S. (2009). Comparison of Three One-Question, Post-Task Usability Questionnaires. 